\title{
INTERACCIÓN VECINAL A TRAVÉS DE FACEBOOK. ANÁLISIS DE UN GASO PRÁCTICO
}

\section{NEIGHBORHOOD INTERACTION THROUGH FACEBOOK. ANALYSIS OF A PRACTICAL CASE}

JUAN GABRIEL GARCÍA HUERTAS

Docente Facultad de Comunicación UFV Director Aula Fotográfica UFV
PABLO GARRIDO PINTADO

Profesor contratado Doctor Facultad de Comunicación UFV

\section{DIEGO BOTAS LEAL}

Director del Grado de Comunicación Audiovisual.

Facultad de Comunicación UFV

Facultad de Comunicación.

Universidad Francisco de Vitoria.

Ctra. Pozuelo a Majadahonda, km 1,800. Pozuelo de

Alarcón, Madrid (España) CP28223

Tlfn: + 34913510303

Email: jg.garcia.prof@ufv.es

p.garrido.prof@ufv.es

d.botas@ufv.es

KEY WORDS

Facebook, Redes sociales, Grupos, ciudad virtual, comunidades, interacción
PALABRAS CLAVES

Facebook, Redes sociales, Grupos, ciudad virtual, comunidades, interacción 


\section{Abstract}

Las relaciones vecinales están en un momento de evolución o cambio. La inclusión de las redes sociales, más concretamente Facebook, ha provocado la aparición de grupos de vecinos que se identifican con su ciudad. Dichos grupos tipo "... No eres de Fuenlabrada sino..." o "Yo soy de Rivas", evolucionan y crecen de una manera sin precedentes y suponen un medio de interacción muy interesante. El objetivo de nuestro estudio es, mediante el método de observación y análisis directo, ver qué tipos de relaciones se dan, y, si contribuyen de una manera significativa a crear comunidad. Para ello nos introduciremos en diferentes grupos de esta red social de una zona determinada de la geografía española, agruparemos los distintos tipos de interacciones virtuales que se realicen y extrapolaremos resultados para sacar conclusiones. De esta manera podremos, no sólo saber qué nivel alcanzan las mismas, sino si ese tipo de relaciones contribuye de alguna manera a la mejora de la vida real frente a la digital. Se trata de analizar si existe una transferencia desde la vida real a la virtual (como se produce al pertenecer a un grupo de Facebook) y de la virtual hacia la real.

\section{Resumen}

Neighborhood relations are at a time of evolution or change. The inclusion of social networks, more specifically Facebook, has led to the appearance of groups of neighbors who identify with their city. These groups "... No eres de Fuenlabrada si no ..." or "Yo soy de Rivas" evolve and grow in an unprecedented way and represent a very interesting interaction medium. The objective of our study is, through the method of observation and direct analysis, to see what types of relationships are given and if they contribute in a meaningful way to create community. For this we will introduce ourselves to different groups of this social network of a certain area of the Spanish geography, group the different types of virtual interactions that are made and extrapolate results to draw conclusions. In this way we cannot only know what level they reach, but also if that type of relationship contributes in some way to the improvement of real life versus the digital analyzed. This is to analyze if there is a transfer from real to virtual life (as it occurs when belonging to a Facebook group) and from the virtual to the real. 


\section{Introducción}

Qué el nacimiento de las redes sociales virtuales ha supuesto una revolución, es ya una realidad en sí misma. Nos encontramos en la primera fase hacia una nueva concepción, no sólo de la forma de comunicarnos, sino incluso del lugar en que nos comunicamos. Surgen nuevos espacios escénicos bajo el calificativo de "virtuales" que presentan nuevas formas de relacionarse. Para Quintana (2001):

La irrupción del digital ha tenido el efecto de una explosión que ha condicionado el devenir del presente y, de forma retroactiva, ha reexaminado la historia de las imágenes en movimiento. hasta cuestionar sus categorías, sus separaciones y su canon.

Lo que en un principio parecía caminar hacia convertirse en un mundo alternativo, ha ido fusionándose con la realidad hasta crear interacciones de tipo virtual-real y real-virtual.Tal como afirma el escritor y filósofo Pierre Lévy (1999), "lo virtual no se opone a lo real, sino a lo actual en cuanto dos formas de ser diferentes (...) Es un real fantasmagórico, latente .Lo posible es idéntico a lo real: Solo le falta la existencia". ${ }^{1}$

El medio internet, a diferencia de la comunicación que ofrecen los medios convencionales como la radio o la prensa escrita, permiten que los usuarios no sean sólo consumidores, sino además, productores de sus propios mensajes. Así, los usuarios pasan a ser generadores de contenido, empleando herramientas como los blogs, videoblogs y las redes sociales. El consumidor-usuario adopta el rol protagonista. Los medios digitales permiten producir su propio contenido y compartirlo sin restricciones. ${ }^{2}$

En este marco, tomando como referencia la red social Facebook y teniendo en cuenta el papel preponderante que tienen los grupos ciudadanos, hemos analizado la actividad de dos grupos. Analizando la interacción del discurso ciudadano en el ámbito real y virtual y detectando si, este proceso, aporta un valor significativo a las ciudades.

\section{Objetivos}

La realización de este estudio, pretende dar una primera visión aproximativa sobre los grupos vecinales en Facebook y su utilidad real actualmente. Las conclusiones que sacaremos del mismo deben invitar a una mayor profundización en el futuro hacia los objetivos marcados.

Buscamos un doble objetivo. Por un lado determinar si son útiles y aportan algo significativo como comunidad dichos grupos o por el contrario, son un foco de discusión, trols e insultos que no lleva a ninguna parte.

Por otro lado, si dichos grupos fuesen útiles, buscaremos analizar que aportan y en que temas se centran para funcionar. Cuáles son los temas a los que más recurre el grupo y ver si se resuelven o no y en qué porcentaje.

Finalmente, un tercer objetivo sería una comparativa. Dado que, como explicamos posteriormente en 
la metodología, hemos elegido dos ciudades con características distintas en población y estructura, ver como se reflejan, si tratan los mismos temas o por el contrario tienen características propias que lo definen.

Con este análisis podremos ver la línea temática que marcan estos grupos vecinales, así como su utilidad y en qué campo. De igual forma, sabremos si esto ocurre igual independientemente de la densidad de población de la ciudad y su área, o por el contrario, es un factor que determina cuáles son los temas de interés de cada una.

\section{Metodología}

Se trata de un estudio comparativo mediante observación directa. Para realizarlo, escogimos una muestra aleatoria que nos permita establecer diferencias y semejanzas entre la actividad en Facebook de un grupo creado de una población grande y otra considerablemente más pequeña.

El estudio se realizó analizando los post de los grupos "No eres de Carranque si no..." como muestra de grupo que representa a una pequeña población y los post de "No eres de Alcorcón si no..." como muestra de grupo creado de una población grande. Dichas publicaciones o post fueron analizadas en ambos casos del 1 al 31 de octubre de 2017.

\section{Muestra escogida}

Hemos seleccionado dos localidades para realizar el estudio: Alcorcón en Madrid y Carranque en la provincia de Toledo.

Carranque, perteneciente a la Comunidad de Castilla la Mancha, se encuentra en la comarca de la Sagra, zona norte de Toledo.

Carranque cuenta con una población de 4612 habitantes censados en 2016 según fuentes INE y su correspondiente grupo de Facebook "No eres de Carranque si no..." cuenta con 1447 miembros. En este caso esto supone algo más de un $31 \%$ de miembros con respecto a su población.

Carranque ha sido tradicionalmente un pueblo de economía eminentemente agrícola aunque, su cercanía con la capital de España le llevó hacia un crecimiento acelerado desde finales de los años 80 . Época en la que contaba con poco más de 800 habitantes.

El peso de la economía sigue siendo el sector primario, aunque, a raíz de la llegada de nuevos vecinos, se ha terciarizado, considerándose, una ciudad dormitorio para muchos trabajadores procedentes del área metropolitana de Madrid.

Alcorcón, ciudad de la zona sur de Madrid. Según el INE (2017) cuenta con una población de 167.354 habitantes. Presenta en Facebook grupos relacionados con la ciudad de muy diversa índole. Tras analizar varios de ellos, determinamos que el grupo "No eres de Alcorcón sino..." es el que más se ajusta al modelo 
participado que hemos definido. Este grupo cuenta, en noviembre de 2017, con 17.938 miembros, lo que supone un $10,7 \%$ de la población. Esto no quiere decir necesariamente que todos los usuarios sean habitantes, pues no es exigencia para pertenecer al grupo. Pero el propio administrador, antes de darte acceso como usuario, pregunta cuál es la relación con el municipio. Alcorcón se presenta además como una ciudad de gran crecimiento desde los años 70 , con carácter industrial.

\begin{tabular}{|c|l|l|}
\hline & Carranque & Alcorcón \\
\hline Población & 4.612 hab. & 167.354 hab. \\
\hline $\begin{array}{c}\text { Usuarios } \\
\text { Grupo Facebook }\end{array}$ & 1.447 usua. & 17.938 usua. \\
\hline Porcentaje & $+/-31 \%$ & $+/-10.7 \%$ \\
\hline
\end{tabular}

Figura 1: Porcentaje de habitantes/usuarios Fuente: elaboración propia

De la misma manera, hemos establecido una serie de variables que nos permitan observar y analizar la actividad y nivel de interacción del grupo de Facebook. Estos aspectos son:

- Número de publicaciones. No tanto por considerarlas relevantes en sí mismas, sino por la posterior estimación en función del número de usuarios que pertenecen al grupo. Que haya un número importante de publicaciones aumentará el muestreo, pero nos centraremos más en las proporciones y tipología de las mismas.

- Porcentaje de publicaciones en comparación con la población estimada. Nos permite en cierta manera medir el impacto del grupo virtual respecto a su población real.

- Naturaleza y contenido de la publicación. Tras un primer análisis, hemos podido crear grupos similares en función de estas variables, dividiéndolo así en "negocio local", "aporta información", "solicita información", "publicación de entretenimiento" y "animales". Con esto, conseguimos cubrir todas las tipologías de publicación en función de la naturaleza de su contenido.

- Grado de publicaciones. En esta variable agrupamos las publicaciones por su peso en porcentaje respecto a las publicaciones de todo el mes, creando grupos de peso.

- Interacción. Sopesado el número de publicaciones de cada tipo, ver si se corresponde con el interés que generan las mismas a través de la interacción que provocan.

- Utilidad de las respuestas. Determinando si las diferentes tipologías de publicación aportan al grupo o generan situaciones de troleo en que tengan que intervenir los administradores o deriven en discusiones que no aportan nada al grupo. 


\section{Los grupos de Facebook como elemento dinamizador de la vida ciudadana.}

Lo conocido como redes sociales lleva ya tiempo entre nosotros, si buscamos una definición, podemos apoyarnos en aquella que lo presenta como una serie de vínculos entre un conjunto definido de actores sociales. Las características de estos vínculos como un todo, tienen la propiedad de proporcionar interpretaciones de la conducta social de los actores implicados en la red. ${ }^{3}$

Con la llegada de la revolución tecnológica, estas propiedades de las redes sociales se han extendido y han crecido de una manera notable hasta convertirse en parte de nuestro día a día.

Surge con esta digitalización un continuo que denominamos interactividad digital, entendiendo a esta como la relación que existe entre las personas que actúan como usuarios de un sistema digital, en la que dicho sistema permite a su vez a otros usuarios mostrar respuestas.

Revisando las líneas descritas por De Kerckhove4, sorprende ver cómo este discípulo de Mc Luhan vaticinó caso a modo visionario la revolución que este concepto iba a traer en el entorno digital. Hoy la comunicación, el entretenimiento y la cultura por citar sólo algunas áreas, se encuentran aderezados por este concepto, que a pesar de ser en múltiples ocasiones una réplica de la realidad material, lejos de actuar como tal, lo revaloriza y pone en no pocas ocasiones por encima incluso de dicha realidad.

De igual modo, muchos son los estudios orientados hacia la definición del concepto de engagement. Un concepto que ha ido ganando el interés de las ciencias sociales ya que, se entiende como un término maleable resultado de la interacción del individuo con el entorno

Sobre todo, ha ganado importancia desde que se incorporó al vocabulario habitual de las empresas que comenzaban a incluir las redes sociales como modo de llegar a su público potencial. El informe Engagement: Understanding Consumers' Relationships with Media (2006) menciona que algunos de los términos que han sido asociados al engagement son involucramiento, conexión, resonancia, pegajosidad, experiencia y relación, entre otros. Es decir, el "engagement no es un concepto unidimensional, que genere fácil acuerdo entre los interesados en explorarlo." 5

Se trata pues de una definición acertada y concreta en el ámbito del marketing, sin embargo, poco válida para nuestro estudio. Los grupos ciudadanos no suelen tener una vocación comercial unívoca. La mayoría de ellos, fueron creados sin un afán lucrativo, con el propósito de proporcionar un servicio a un grupo potencial de gente que comparte unos orígenes o un lugar de residencia.

Es por ello que, en este caso, nos acercamos más a conceptos como experiencia y relación. De ahí que el análisis esté enfocado a clasificar y analizar las publicaciones y el grado de interacción (comentarios, veces compartido o me gusta) que han generado.La observación de estas variables nos ayudará a determinar si estos grupos son útiles o, por el contrario, no aportan nada a la población y son foco de discusiones y burlas 
entre sus componentes.

Hemos seleccionado dos ciudades para realizar el estudio. En primer lugar, Alcorcón, ciudad de la zona sur de Madrid con una población de 167.354 habitantes censados en el año 2017 según fuentes INE del año 2015. Presenta en Facebook grupos relacionados con la ciudad de muy diversa índole. Tras analizar varios de ellos, pensamos que aquel que menos se especializaba en un área concreta, dejando al usuario elegir el tema a consultar es el perteneciente a los denominados "No eres de...". En este caso concreto, se trata del grupo "No eres de Alcorcón sino...". En noviembre de 2017 cuenta con 17.938 miembros, lo que supone un $10,7 \%$ de la población. Esto no quiere decir necesariamente que todos los usuarios sean habitantes, pues no es exigencia para pertenecer al grupo. Pero el propio administrador, antes de darte acceso como usuario, pregunta cuál es la relación con el municipio, y el análisis posterior de las publicaciones, dejan intuir claramente que en la mayoría de las ocasiones son habitantes del municipio o con una relación habitual dentro del mismo.

Alcorcón se presenta además como una ciudad de gran crecimiento desde los años 70 , con carácter industrial.

Por otro lado, escogimos el pueblo de Carranque, perteneciente a la Comunidad de Castilla la Mancha, concretamente en la zona norte de Toledo. Dicho pueblo se encuentra a escasos 33 kilómetros de la ciudad de Alcorcón, pero las diferencias demográficas como veremos son notables.

Carranque cuenta con una población de 4612 habitantes censados en 2016 según fuentes INE6 y su correspondiente grupo de Facebook "No eres de Carranque si no..." cuenta con 1447 miembros. En este caso esto supone algo más de un $31 \%$ de miembros con respecto a su población. Primer dato significativo, el porcentaje de miembros respecto a la población es inversamente proporcional. A menor población, mayor porcentaje de usuarios en el grupo.

Carranque ha sido tradicionalmente un pueblo agrícola aunque su cercanía con la capital de España le llevó hacia un crecimiento desde los años 80 en que apenas llegaba a 800 habitantes hasta la población mencionada a día de hoy. Sigue teniendo una economía agrícola aunque en los últimos años se le ha calificado como "Ciudad dormitorio" para madrileños.

Centrémonos ahora en el análisis de cada uno de los grupos por separado.

\subsection{Análisis de las publicaciones de grupo A de Facebook: Carranque (Toledo).}

Para llevar a cabo este análisis hemos seleccionado aleatoriamente el mes de Octubre de 2017 para ambos grupos. Se han contabilizado el número de publicaciones en dicho mes y analizado su contenido dividiéndolo en: negocio local, aporta información, solicita información, post de entretenimiento, animales. Todas las publicaciones han podido ser clasificadas según estos términos. 
Las publicaciones referentes a "negocio local", se han englobado todas las publicaciones relativas a ofertas, anuncios o puesta en conocimiento de los usuarios de negocios de ámbito local o de otros municipios, pero cuyo dueño vive en Carranque. Estas publicaciones suponen un 39,6 \% de las publicaciones en el mes analizado, en raras ocasiones genera algún comentario y no suele obtener más de tres"me gusta". Se presenta pues esta opción como publicaciones informativas. Bajo este prisma el grupo es aprovechado como oportunidad de publicidad sin coste para los negocios locales y, por lo analizado en los comentarios, es agradecido por los usuarios.

En segundo lugar establecimos la categoría de publicaciones que "aportan información". Estas, a diferencia de la de negocios locales, son publicaciones acerca de distintas actividades que se producen en el municipio o de experiencias en locales y negocios de los usuarios sin llegar a poder considerarse publicidad como tal sino experiencia de usuario. Durante el periodo analizado, estas suponen un 15,8 \% del total. Estas publicaciones tienen un nivel de interacción similar a las anteriores, aunque, llama la atención que los comentarios y "me gusta" aumentan si se trata de algún tipo de información a modo de denuncia sobre deterioro o mejora de servicios públicos en el municipio. Ahora bien, normalmente, las interacciones no caen en comentarios insultantes o con tendencia a la desviación, sino que suelen mostrar diferentes puntos de vista sin caer en el menosprecio.

En tercer lugar, hemos clasificado algunas publicaciones como "solicita información". Estas suponen algo menos del $27 \%$ de las publicaciones. Lo primero que llama nuestra atención es el número de comentarios recibidos en las publicaciones de este tipo, llegando a multiplicarse por hasta diez con respecto a los tipos de publicaciones anteriores. La mayoría de estas solicitan algún tipo de ayuda para buscar profesionales de diferentes ámbitos y la comunidad virtual se vuelca aportando datos y su propia experiencia. La utilidad de estas publicaciones es pues innegable, ninguna de las consultas queda sin respuesta.

En cuarto lugar, las publicaciones sobre "animales". Suponen un 14,3 \%. Estas publicaciones, podrían a su vez subdividirse en dos categorías, una de compra, venta y regalo y otra en lo referente a animales perdidos. 


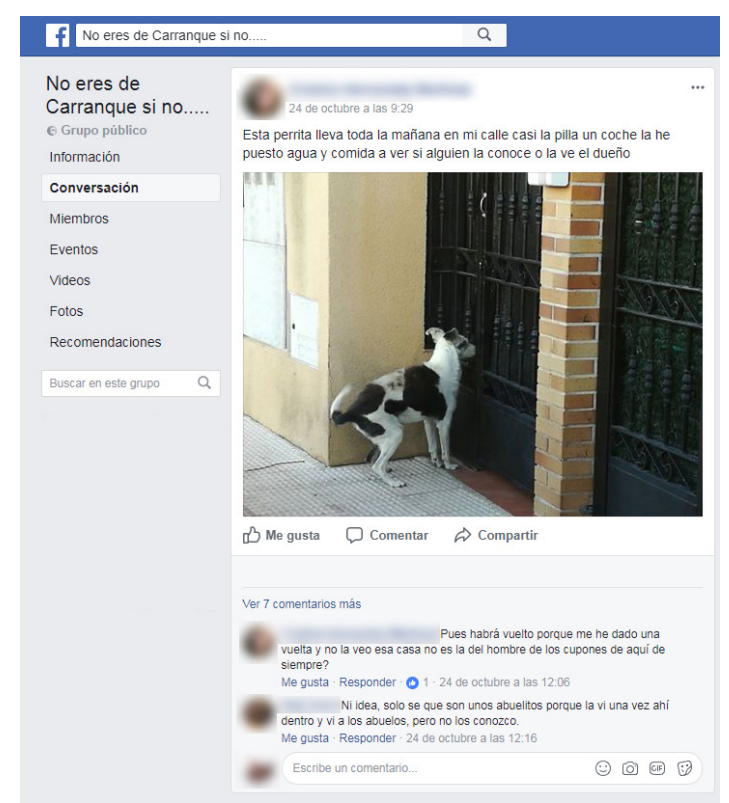

Imagen 1: Captura de grupo Facebook. Grupo tipo: Animal

La primera de ellas apenas recibe comentarios y algún que otro "me gusta", la segunda sin embargo si se presenta más activa. Aunque su número no nos permite ser concluyentes si hace ver una mayor sensibilidad cuando se trata de encontrar a la mascota de un vecino.

Finalmente las publicaciones de "entretenimiento", que suponen poco más del $3 \%$. Estas parten de fotografías del municipio y acertijos o chistes que suben los usuarios. Las fotografías suelen presentar comentarios de admiración o nostalgia mientras que acertijos o chistes reciben "me gusta" sin comentarios algunos.

\begin{tabular}{|c|c|}
\hline & Carranque \\
\hline Negocio local & $39,6 \%$ \\
\hline $\begin{array}{c}\text { Aportan } \\
\text { información }\end{array}$ & $15,8 \%$ \\
\hline $\begin{array}{c}\text { Solicitan } \\
\text { información }\end{array}$ & $27 \%$ \\
\hline Animales & $14,3 \%$ \\
\hline Entretenimiento & $3,3 \%$ \\
\hline
\end{tabular}

Figura 2: Porcentajes de tipología de publicación en el grupo A: Carranque Fuente: elaboración propia 


\subsection{Análisis de las publicaciones de grupo B de Facebook: Alcorcón.}

Bajo la agrupación de las mismas tipologías de publicación empleadas en el grupo A, llevamos a cabo el análisis de otro grupo de Facebook, pero en esta ocasión de una gran urbe con más de 160.000 habitantes.

El número de publicaciones se dispara de manera considerable con respecto al grupo A. En esta ocasión nos encontramos con más de 300 publicaciones en el mismo mes que apenas superó las 60 en el grupo de Carranque. A pesar de que el porcentaje de usuarios respecto a la población es sensiblemente inferior para Alcorcón, bien por el número de habitantes o bien por la actividad de los mismos, el número de publicaciones alcanza otra dimensión.

Pero esta primera impresión gira 180 grados si ponemos en contraste el número de usuarios del grupo frente al número de publicaciones. Así esta relación supone un 4,3\% en el caso de Carranque, frente al 1,7\% para Alcorcón.

En relación con el número de usuarios inscritos, la actividad del grupo se supone mayor en la ciudad pequeña o pueblo.

Centrémonos ahora en la clasificación de tipologías de publicación. En lo referente a "negocios locales" el $27,1 \%$ de las publicaciones están dentro de este grupo y presentan un comportamiento respecto a los comentarios y "me gusta" bastante escaso. En rara ocasión vemos algún comentario y si lo hay es mostrando interés por el producto del negocio.

Cumple una utilidad similar a la del grupo A, se presenta para el comerciante como una manera gratuita de publicitarse y aporta información de negocios locales al usuario.

Por otro lado, el grupo que "aportan información" supone un $22.5 \%$ y llama la atención que, para este tipo de publicaciones que aportan información sobre actividades en el municipio, hay un alto índice de participación en forma de comentarios y "me gusta". Dichos comentarios van en la línea de comentar actividades anteriores del mismo tipo o solicitar más información o formas de inscribirse o ir, generando pequeños grupos de información que ayudan a los usuarios a decidirse.

Con respecto al tercer grupo, el denominado "solicita información", estas publicaciones suponen un $36,1 \%$ con respecto al total del mes y son las que mayor índice de comentarios presenta. De nuevo aparecen los grupos de Facebook como una oportunidad cooperativa de obtener información. Los usuarios se vuelcan en aportar la información solicitada e incluso llegan a etiquetar a gente que puede estar interesada en esa misma información.

Pasando ya al cuarto grupo "animales", estas publicaciones suponen un 4,5\% de las totales del mes y tienen un comportamiento dividido. Cuando se trata de animales perdidos, suben los comentarios bien dando ánimos o bien aportando algo de información. Sin embargo, cuando se habla de vender o regalar animales, 
los comentarios son prácticamente nulos y sólo resaltan algunos "me gusta". Comprobamos que, siendo el porcentaje de publicaciones mucho menor con respecto al otro grupo, el comportamiento es similar.

Finalmente, el último grupo, "entretenimiento", suponen algo menos del 10\%. Cabe destacar que en la mayoría de las ocasiones estas publicaciones están hechas por los propios administradores buscando algo de nostalgia en el grupo pues suelen ser fotografías de barrios emblemáticos o edificios y negocios que recuerdan otros tiempos. De cualquier forma, hablamos de un porcentaje sensiblemente mayor con respecto al otro grupo y que además genera bastantes comentarios en la misma línea nostálgica que la publicación.

Recopilando pues estos datos nos encontramos con tres grupos de peso importantes, los referidos a negocios locales, aquellos que aportan información y los que la solicitan. Los tres están por encima del 20\% en cuanto a peso de porcentaje. Por debajo, de manera significativa entretenimiento y animales. Esto nos permite obtener una primera impresión sobre la que trabajar en el posterior punto en la comparativa entre grupos.

\begin{tabular}{|c|c|}
\hline & Alcorcón \\
\hline Negocio local & $27,1 \%$ \\
\hline $\begin{array}{c}\text { Aportan } \\
\text { información }\end{array}$ & $22,5 \%$ \\
\hline $\begin{array}{c}\text { Solicitan } \\
\text { información }\end{array}$ & $36,1 \%$ \\
\hline Animales & $4,5 \%$ \\
\hline Entretenimiento & $9,8 \%$ \\
\hline
\end{tabular}

Figura 3: Porcentajes de tipología de publicación en el grupo B: Alcorcón Fuente: elaboración propia

\subsection{Comparativa de datos recopilados de ambos grupos.}

Comenzando por las publicaciones tipo "Negocio local", el grupo A presenta un 39,6\% frente al 27,1\% del grupo B. En ambos casos se encuentran entre los dos tipos de publicación más habituales. La primera para el grupo A y segunda para el B. Sin embargo, son publicaciones que generan poco movimiento. En ambos casos los comentarios son escasos al igual que los "me gusta". Ambos administradores ponen el filtro de que deben tratarse de negocios locales o negocios cercanos creados de alguien perteneciente al municipio. Cómo hemos dicho con anterioridad, su utilidad parece orientarse más hacia la pura publicidad gratuita y para saber del verdadero interés de estas por parte del grupo, sería conveniente lanzar algún tipo de encuesta dentro del propio grupo. Con los datos actuales estas publicaciones parecen generar poco interés y participación, pero desconocemos la apreciación de las mismas por parte de los usuarios del grupo. 
En lo que respecta a las publicaciones del tipo "aportan información", en ambos casos ocupan el tercer lugar en cuanto a volumen de publicaciones en el mes, pero con porcentajes muy distintos. En el grupo A, tiene un $15,8 \%$ frente al $22,5 \%$ del grupo B. En ambos casos, son de las publicaciones que más interactividad generan. Obtienen un buen número de comentarios en la línea de hablar sobre sus experiencias, generar apoyo o comentar la información dada. En este tipo de publicaciones los usuarios parecen mucho más activos en ambos casos, de lo que podemos deducir que generan mayor interés.

Para el tercer tipo de publicaciones, "solicita información" el grupo A presenta un 27\% frente al 36,1\% del grupo B. En ambos casos son un porcentaje importante de las publicaciones, llegando a ser incluso el tipo de publicación más repetida en el caso del grupo B. Al igual que con las publicaciones que "aportan información", en este tipo nos encontramos con un número mayor de interacción en forma de comentarios tanto para el grupo A como para el grupo B. Podemos llegar a la conclusión que frente a los anuncios de negocios locales, las informaciones creadas o solicitadas por los propios componentes del grupo generan mayor interés y dan pie a una mayor colaboración por parte de los mismos.

Pasamos ya a las publicaciones agrupadas como "animales", dónde se producen unos porcentajes de diferente interpretación en función del grupo. Así, el grupo A, recordemos de menor población y entorno rural, este tipo de publicaciones suponen un 14,3\%. Muy próximo al porcentaje de las publicaciones tipo "aportan información" emplazadas ambas en un segundo grado de importancia por número de entradas. No ocurre así en el grupo $\mathrm{B}$, donde el porcentaje de este tipo de publicaciones se reduce a un $4,5 \%$ quedando relegado a un tercer grado en cuanto a importancia por número de entradas. Sin embargo, a pesar de presentar porcentajes distintos, ambos muestran el mismo comportamiento. Cuando se trata de animal perdido, el grupo muestra solidaridad y ayuda en la medida de sus posibilidades, no siendo así si hablamos de compra, venta o regalo, donde la actividad en forma de comentarios es prácticamente nula. Analizaremos posteriormente en las conclusiones esta diferencia.

Finalmente, el grupo de publicaciones de "entretenimiento" que muestra el número más bajo de publicaciones. Un 3,3\% para el grupo A y un 9,8 para el B. Curioso dato teniendo en cuenta que estos grupos de Facebook nacen con un aire de nostalgia de la mano de compartir experiencias pasada e imágenes y sin embargo lo que podía definir este tipo de publicaciones, son las menos llevadas a cabo. Como comentamos con anterioridad el casi $10 \%$ del grupo B está forzado por parte de los administradores, que son quienes suben la mayoría de estas publicaciones. No obstante es cierto que las pocas publicaciones que hay sí generan interactividad en forma de comentarios y "me gusta" pero por otro lado, son publicaciones que no generan por sí mismos los propios componentes o usuarios del grupo.

\section{Conclusiones}

En primer lugar, observando ambos grupos, vemos cómo de las clasificaciones marcadas por la tipología de publicación se reducen a 3 grandes grupos. Uno primero, formado por las publicaciones de tipo "negocio local" y "solicita información" que en ambos grupos superan el $50 \%$ de las publicaciones del mes. Sin 
embargo, se produce un comportamiento curioso: el grupo con menos usuarios y menor población, el referido al grupo A de Carranque contiene casi un $40 \%$ de las publicaciones de negocios locales, no siendo así en el grupo B de Alcorcón donde estas publicaciones suponen un $27,1 \%$ del total a pesar de tener muchos más usuarios y ser una ciudad mucho más poblado.

Las publicaciones referidas a "negocios" generan muy pocos comentarios. No obstante, se trata de una mera apreciación que debe ser validada en una segunda fase de este estudio.

Respecto a las publicaciones del tipo "solicita información", son las que más interacción generan por comentarios, respuestas y "me gusta" y se sitúan en ambos casos dentro de este primer gran grupo de publicaciones que ya hemos clasificado. Además de saber que ante la solicitud de información, los usuarios se vuelcan en aportar algo que ayude al que pregunta, luego la utilidad de las mismas queda demostrada generando además un sentimiento de pertenencia al grupo.

Existe un comportamiento dispar en las publicaciones donde se "aporta información". Las primeras observaciones nos llevan a pensar que la naturaleza de la publicación y las características de cada grupo de Facebook, hace que para los usuarios de uno sean más interesantes que para los del otro. Por poner un ejemplo práctico, las actividades de las que se informa en una ciudad de 167.000 habitantes son muy diferentes de las que encontramos en el grupo de un pueblo de algo más de 4.000 .

De una manera aún más notable, encontramos la misma situación para las publicaciones referidas a "animales". En esta clasificación, el 14,3\% del grupo A contrasta con el 4,5\% del grupo B, presentando el mismo tipo de contenido, por un lado compra-venta y regalo de mascotas y por otro pérdida de animales. Aunque el comportamiento de los usuarios es el mismo en ambos casos, mostrando mayor interactividad frente a los casos de pérdida o abandono para ayudar o preguntar por la situación y dejando en algunos "me gusta" los casos de compra-venta.

La situación geográfica de la población a que se refiere cada uno de los grupos quizás nos dé un indicativo de la razón de esta diferencia. El grupo A es un pueblo como comentamos eminentemente agrícola y rodeado de terreno sin construir, de labranza, dónde parece haber una mayor concienciación con el mundo animal frente al grupo $B$, una gran urbe en que los espacios naturales son parques y en su mayoría con prohibición de llevar a los animales sueltos.

Finalmente el grupo de publicaciones de "entretenimiento" supone en líneas generales algo mucho menor. Como ya hemos mencionado, el mayor porcentaje de publicaciones de este tipo en el grupo de Alcorcón, obedece a la insistencia de los administradores que, a menudo, postean imágenes y fotografías del pasado. En el grupo A, las publicaciones de este tipo son casi inexistentes (3,3\%). Ahora bien, en ambos casos, generan un alto grado de interacción con la audiencia.

Así pues, tras analizar cada uno de los grupos por separado y si buscamos una visión más amplia, el grupo de Facebook A, Carranque, podría ser dividido en tres grados de importancia por número de 
publicaciones, dónde el primer grado estaría comprendido por "negocio local" y "solicitan información" y sumando entre ambas el $66,6 \%$ de las publicaciones. Un segundo grado donde están las publicaciones de tipo "Aportan información" y "animales" con un 30.1\% y un tercer grado con las de "entretenimiento" con un $3,3 \%$. Estos porcentajes no se corresponden de manera directa con la interactividad generada, pues en esto publicaciones del tipo "animales" y "solicitan información" se presentan como las más activas.

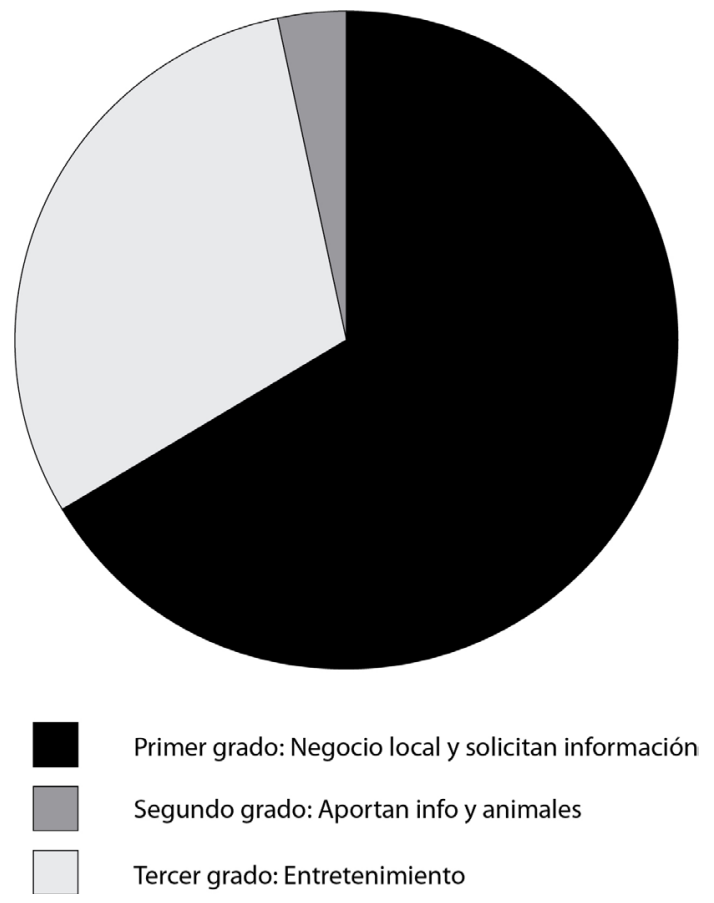

Figura 4: Clasificación en grados según \% de publicaciones. Fuente: elaboración propia

En el grupo B (Alcorcón), las publicaciones sobre "negocio local", "aportan información" y "solicitan información" suman el 85,7\%. La observación de estos datos nos permite intuir que los usuarios de este grupo publican más en busca de obtención o para facilitar información que para cualquier otra actividad.

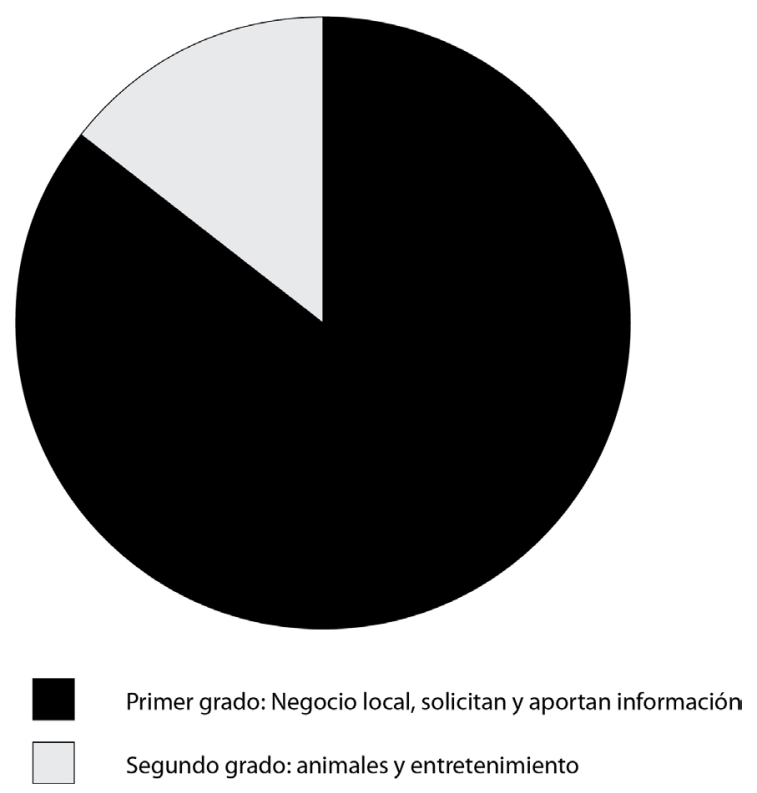

Figura 5: Clasificación en grados según \% de publicaciones. Fuente: elaboración propia 
Podemos decir pues, que la utilidad de cada una de las publicaciones está presente, pues todas parecen aportar algo a esta comunidad virtual, pero que en muchas ocasiones el número de publicaciones no se corresponde necesariamente con la respuesta del resto de usuarios. Los grupos de Facebook vecinales, se presentan como útiles en cuanto que aportan algo a la vida real de los usuarios, se emplean como transferencia de lo real a lo virtual y de lo virtual a lo real de manera constante y ahí reside su principal utilidad como medio. Permite la interacción e intercambio de información a modo multimedia y en tiempo real no sin que también se permita cierta atemporalidad que otros medios no pueden ofrecer.

La influencia de los administradores es clave, ya no sólo en la criba que pueden ejercer sobre determinadas publicaciones permitiendo así una "sana" convivencia virtual, sino con la agrupación temática y la derivación de algunos usuarios hacia temas que ya fueron tratados a través de los conocidos hashtags.

Podemos concluir que la naturaleza real del vecindario, pueblo o ciudad por el que fue creado el grupo marca el estilo de publicación que encontraremos en el grupo de Facebook, así como las interacciones que estas provocan.

El estudio abre la puerta a líneas de investigación más profundas tales como qué tipo de publicaciones pueden generar o generan mayo interactividad y si se corresponde con el interés real de los usuarios de los grupos.

Otra interesante línea sería profundizar en cómo influye en la tipología de los grupos virtuales las características reales de la población que se siente representada en él.

Por el momento lo estudiado nos presenta unos grupos virtuales que hablan de temas similares, pero a priori parecen presentar intereses diferentes dentro de estos temas. Temas que sin lugar a dudas en cualquier caso contribuyen a crear ese sentimiento de pertenencia al grupo no sólo virtual sino cómo parte del municipio real.

\section{Referencias}

- 1 Lévy, P., \& Levis, D. (1999). ¿ Qué es lo virtual?. Barcelona: Paidós.

- 2 Garrido, P.(2009). Agencias de viaje online: situación y perspectivas en el comercio electrónico español. Universidad Complutense de Madrid, Servicio de publicaciones.

- 3 Requena Santos, F. (2012). Análisis de redes sociales: Orígenes, teorías y aplicaciones. Madrid. Centro de investigaciones sociológicas.

- 4 De Kerckhove, D. (2009). Inteligencias en conexión, hacia una sociedad de la web. Barcelona. Gedisa.

- 5 González-Bernal, M. I. (2016). Hacia la comprensión del engagement de las audiencias de televisión, modelo conceptual multidimensional desde la comunicación. Colombia, Universidad de la Sabana. 
